\title{
Incorporating Crystallography into a Short-Term Research Experience
}

Dean Johnston (djohnston@otterbein.edu)

The Advanced Laboratory course at Otterbein University is a required course combining a set of fourweek research rotations with integrated scientific writing and presentation activities. The challenge from a faculty member's perspective is designing a time-limited research experience involving students with a wide range of prior coursework. I will describe how our students explored the preparation of ionic cocrystals of a variety of drug or drug-like molecules that they then subsequently characterized by powder and single-crystal X-ray diffraction, DSC, TGA and FTIR. Six new crystal structures (along with several redeterminations) were completed in the course of the one semester course.

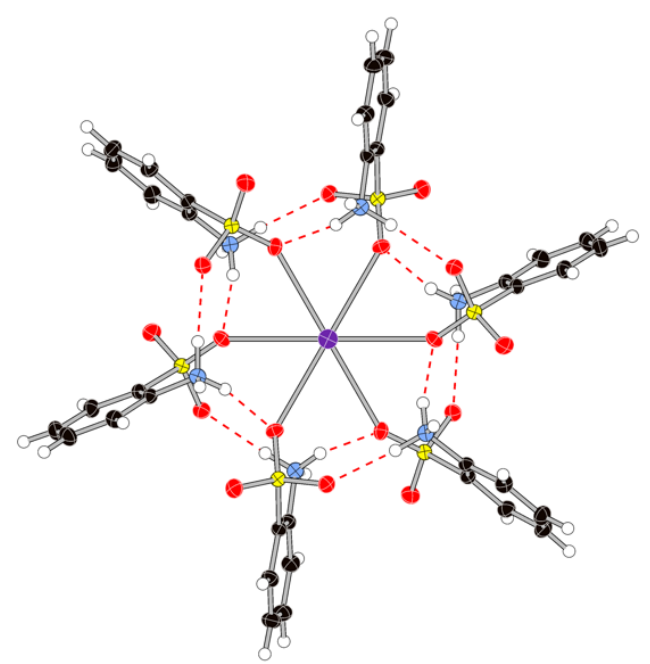

While not a crystallography course, the research experience required that students become familiar with crystal-growing techniques, solventassisted mechanochemistry, unit cell determination, basic X-ray sample handling and processing and structural database searching. The experiments were well-suited to the limited time scale of the course, engaging to students of diverse interests and experimentally accessible. 